Meta

Journal des traducteurs

Translators' Journal

\title{
La mort d'un maître, Georges Mounin (1910-1993)
}

\section{Claude Tatilon}

Volume 38, numéro 2, juin 1993

URI : https://id.erudit.org/iderudit/004564ar

DOI : https://doi.org/10.7202/004564ar

Aller au sommaire du numéro

Éditeur(s)

Les Presses de l'Université de Montréal

ISSN

0026-0452 (imprimé)

1492-1421 (numérique)

Découvrir la revue

Citer cette note

Tatilon, C. (1993). La mort d'un maître, Georges Mounin (1910-1993). Meta, 38(2), 391-392. https://doi.org/10.7202/004564ar d'utilisation que vous pouvez consulter en ligne.

https://apropos.erudit.org/fr/usagers/politique-dutilisation/ 


\section{LA MORT D'UN MAîTRE \\ Georges Mounin (1910-1993)}

Georges Mounin est mort le 10 janvier dernier. Je me refuse à dire qu'il «s'est éteint» ou qu'il «a été enlevé à notre affection»: il n'aurait pas aimé. Car Georges Mounin était avant tout un démystificateur du langage. Linguiste, sémiologue, critique de poésie, traducteur à la fois théoricien et praticien, il nous laisse en héritage une importante somme d'écrits sur la langue et ses divers emplois, dans lesquels il met toujours un point d'honneur - même parvenu au faîte de la notoriété publique - à rendre à André Martinet, chef de file de la linguistique fonctionnelle, ce qui lui appartient en propre. Bel exemple de modestie et de probité intellectuelle.

La lecture de Georges Mounin donne à réfléchir sur bien des aspects de la communication humaine: le mystère de la poésie, les mécanismes de la traduction, ceux des communications non verbales... Linguiste, il nous fait prendre conscience du fait que la langue, instrument d'une efficacité incomparable, ne se caractérise pas par une «pureté» tout imaginaire: chargée d'«impuretés» (si l'on y tient) constitutives et impossibles à éliminer, elle permet de produire un discours toujours ouvert à une pluralité d'interprétations. L'incertitude, l'ambivalence, l'ambiguïté sont le lot 
naturel de nos échanges verbaux, et non des «accidents» qui viendraient en perturber le fonctionnement «naturel». Ces insuffisances communicatives, il faut les accepter, faute de pouvoir les éliminer - mais toujours en nous efforçant d'en réduire le plus possible les effets parasites. Et admettre que dire, «dénoter» notre vaste et mouvant univers, ne signifie pas le décrire par le menu, mais simplement l'évoquer, le rendre présent à la conscience, de façon économique et arbitraire.

Cette réflexion, que je crois fidèle à l'enseignement de Georges Mounin, nous conduit tout droit au débat très contemporain sur le langage dit «politiquement correct»: grossière utopie, tout embarrassée d'inutiles circonlocutions. Un seul exemple, «d'une brûlante actualité» : quel mal y a-t-il à abandonner un instant un ami sur le bord du trottoir en lui disant: «Excuse-moi, je vais aider l'avengle à traverser.» La cécité de la personne n'est-elle pas précisément, dans une telle circonstance, le «trait situationnel pertinent»? Serait-il déplacé, comme d'aucuns voudraient nous le faire croire, d'expliciter ce trait dans l'énoncé? Si je me résous à dire: «aider cette person$n e$ à traverser», en évitant de mentionner son infirmité (l'anglais «dans le vent» me suggère pour ce nom tabou défi physique, physically challenged person!), ma phrase ne me satisfait plus: la fausse pudeur (l'infirmité en question serait-elle une maladie honteuse justifiant que je choisisse «des mots pour la cacher»? sonne bizarre à mon oreille. Quant à savoir s'il faut s'adresser à la personne en lui disant : «mon pauvre Monsieur!» ou «ma pauvre Dame !», ce n'est plus une question de langue mais bien de tact.

Soyons raisonnables, cessons de faire du strabisme métalinguistique en fixant les mots de trop près. Relisons plutôt les nombreux commentaires que fait Georges Mounin sur ce qu'il appelle pittoresquement $I$ '«inflation verbale» et les «rougeoles terminologiques». Dans une certaine mesure, il est possible - souhaitable même - d'infléchir l'usage linguistique vers plus de justice sociale et plus de précision référentielle (en cessant, par exemple, d'utiliser des clichés désobligeants à l'encontre des femmes, ou en acceptant de les désigner par des titres au féminin qui correspondent aux fonctions qu'elles exercent aujourd'hui). Mais la langue possède des limites qu'il ne faut pas (pour la souveraine clarté de la communication) dépasser : celle de «l'arbitraire du signe», qui assure un fonctionnement économique, et celle des contraintes grammaticales, qui en garantissent la solidité.

Je ne peux hélas pas prétendre aujourd'hui que Georges Mounin aurait approuvé sans réserves les lignes qui précèdent. Mais je peux déclarer avec certitude que je ne les aurais pas écrites si je ne l'avais pas connu et lu - et qu'à bien des égards sa lecture m'a ouvert les yeux.

Georges Mounin, un maître à penser. Lui disparu, il nous reste son œuvre, vaste, profondément humaine.

Claude Tatilon Université York, Toronto, Canada 